\title{
Counting Demons and Devas: Addendum to "Solstice Alignments at Angkor Wat: Connecting to the Cycles of Time"
}

\section{William F. Romain}

Independent Scholar

romainwf@aol.com

\begin{abstract}
In the article referenced below and published earlier in Journal of Skyscape Archaeology 4 (2), discussion was presented concerning the bas-relief at Angkor Wat known as the "Churning of the Ocean of Milk". The present paper clarifies certain points in the original discussion and provides additional details concerning the posited day-count between equinox and solstices as represented in the relief.
\end{abstract}

Keywords: Angkor Wat; equinox; solstice

In an earlier article (Romain 2018), I explained, following Mannikka (1996), how the solstices appear represented in the Angkor Wat bas relief known as the "Churning of the Ocean of Milk". The relief depicts a well-known Hindu creation myth found in the Vishnu Purana (1.9, in Wilson 2014 [1864], 75-76) and other texts (Figure 1).

Discussion concerning the relief was in support of the main thesis of the article, which is that the solstice directions are memorialised in the architecture of Angkor Wat and nearby temples. As will be recalled, the Angkor Wat relief shows two opposing groups of deities (88 or 89 devas and 91 or 92 asuras) pulling back and forth on a churning rope (in the form of the serpent god, Vasuki) wrapped around Mount Mandara, which is used as the churning stick. This churning stick has been plunged into the Ocean of Milk; Vishnu, the Preserver, presides at the centre of the scene while Indra, king of Heaven and of the devas, floats above. Apsaras (beautiful female dancers and singers) flank the image while Kurma, the turtle, supports the cosmic mountain (Figure 2). The objective of the churning was to create an elixir of immortality. In addition to successfully creating the elixir, many other special treasures and lesser gods were created. The story continues from there. 


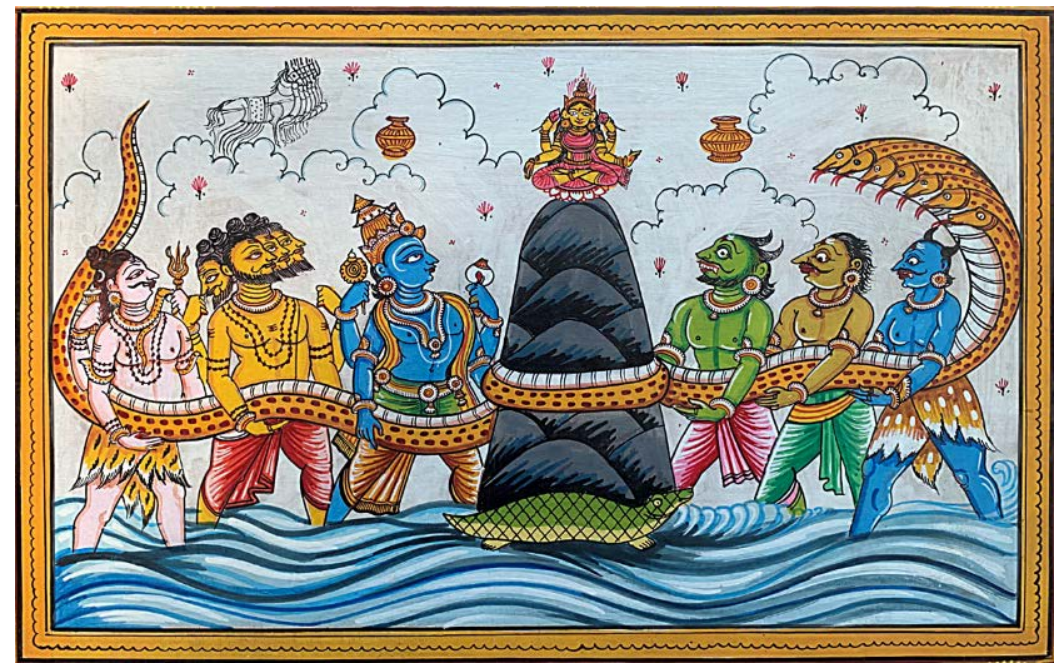

FIGURE 1. Modern folk art depicting Churning of Ocean of Milk story. Watercolour by Rabi Behera in author's collection. Photo by author. Only large deities shown. Not shown are smaller individual day count devas and asuras.

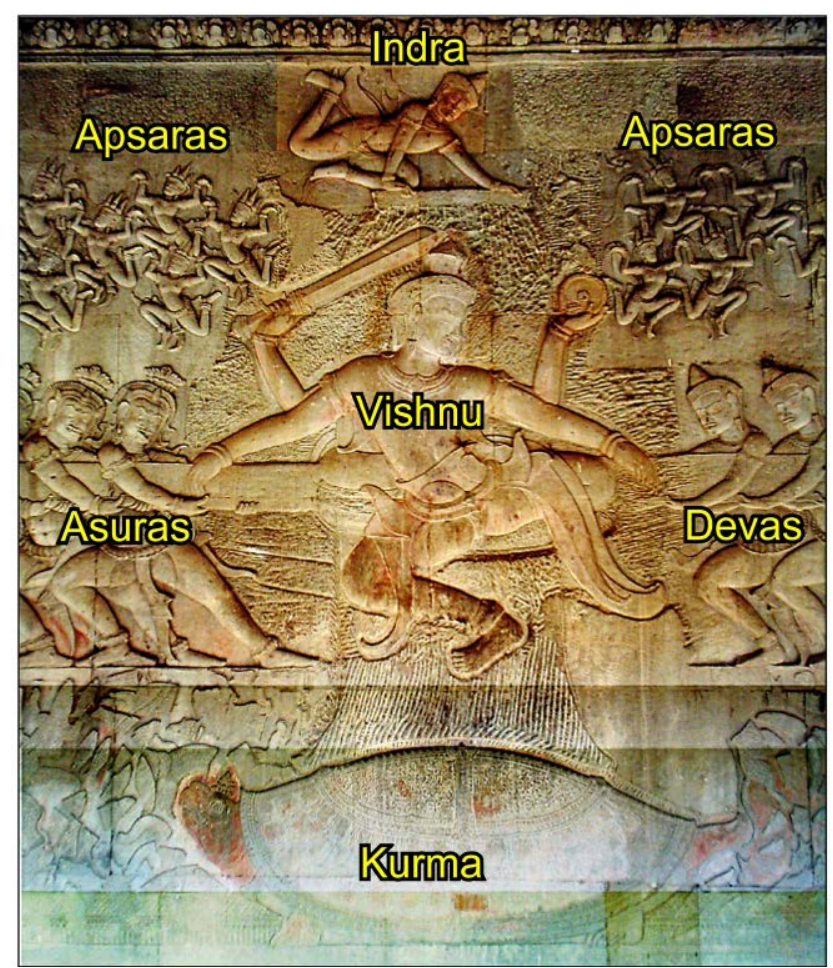

FIGURE 2. Detail from the "Churning of the Ocean of Milk" bas relief at Angkor Wat (photograph by Markalexander100, uploaded to Wikimedia Commons in 2005. Annotations added by author. https:// commons.wikimedia.org/wiki/File:Awatoceanofmilk01.JPG). 
According to Mannikka (1996), as a result of where the relief is situated (south wing, east wall, third gallery) and the way associated gallery pillars are positioned, over the course of a year sunlight from the solstices will illuminate the deities at either end of the serpent-rope. At winter solstice, sunlight falls on Bali, the leader of the asuras, who is shown holding the head of the serpent (Mannikka 1996, fig. 5.38); and at summer solstice, the light falls on Sugriva, who holds the tail of the serpent (Mannikka 1996, fig. 5.43). At the equinoxes, the Sun illuminates Vishnu at the centre (Mannikka 1996, 162). Together, the panel elements symbolise the relationships between the equinoxes and solstices.

Additionally, Mannikka (1996, 37-41) proposes that the relief shows the relationships between seasons as delineated by the number of days between the equinoxes and solstices.

The 91 asuras in the south represent the 91 days from equinox to winter solstice [...], and the 88 northern devas represent the 88 days from equinox to summer solstice. [...] In fact, there are either 88 or 89 devas in the scene, 89 if the deva atop Mount Mandara is counted with the others. There are 88 or 89 days from the spring equinox, counted from the first day of the new year, to the summer solstice. (Mannika 1996, 37)

Of course, the astute reader will recognise that the asura and deva counts of 91 or 92 and 88 or 89 on the panel do not exactly correspond to the number of days between events as reckoned by the calendar with which we are most familiar. According to the Gregorian calendar for 2019, for example, the autumn equinox occurs on 23rd September, while the winter solstice occurs on 21st December (Time and Date 2019). If 24 September is considered day 1 in a day count, then the winter solstice falls on day 90 . However, the 2019 vernal equinox occurs on 20th March, and the summer solstice on 21st June, meaning that if 21st March is considered day 1 in a day count, then the summer solstice falls on day 94.

A possible solution to the differing counts is found at the point when the day count begins. Beginning with analysis of the southern part of the Angkor Wat relief, there are 91 asuras situated between the pivot point and the oversized figure of Bali at the end. If we count the number of days from the autumn equinox to the winter solstice (to include the start and end dates of 23rd September and 21st December, respectively), then we arrive at a day count of 91 days which corresponds to the number of asuras shown (again excluding Bali). It also happens that the number of days from the winter solstice to vernal equinox (including start and end days) is 91.

Analysis of the relief panel on the north side is more complicated. Based on Faraut (1910), Mannikka (1996, 37-39) explains:

In Cambodia, the spring equinox (beginning of the sun's yearly journey) lasted for 3 or 4 days: Thngai Chaul, "day of entry," Vone Bat, "day(s) of the middle," and the last day, the Langsak. The Langsak, the first day of the new year, occurred 3 or 4 days after the spring equinox, depending on the year. [...] Mount Mandara as the churning point would symbolize the 3 or 4 days of the equinox period.

Today, three of these days are known as Maha Sangkran, Vireak Vanabat and T'ngai Loeng Sak, and they are celebrated together as a major festival. 
In Cambodia's present-day Buddhist calendar, New Year is around mid-April. However, this was introduced after the demise of Angkor Wat, which was modelled on Hindu cosmology. The calendar that was in use during Angkor times had New Year in December. Either way, however, it remains the same that "the average duration of the year is fixed by the time between the two Langsak days" (Faraut 1910, 17, my translation).

Given the above, if the north panel day count starts three or four days after 20th March, then the number of days in the day count is 94 minus 3 or 4, which equals 91 or 90 . This is not the end of the calculation, however. Given that a start day was already included in the count on the southern panel, we do not include it in the present count. In fact, we can subtract that one day from the above-noted 91 or 90 . The result is 90 or 89 days, the latter of which is equal to the number of devas shown on the panel (to include Indra).

Admittedly, a potential problem is that we do not know how far back in history the three- or four-day Maha Sangkran-Vireak Vanabat-T'ngai Loeng Sak festival was celebrated. Angkor Wat was built during the reign of Suryavarman II (1113-c. 1150 AD). Years later, in 1296 AD, the Chinese envoy Zhou Daguan (Zhou 2007, 63 [Chapter 13, "New Year and Other Times of Year"]) mentioned a 15-day New Year festival in Cambodia. From this, we know that New Year festivals were multi-day events at least as early as the thirteenth century.

Another question revolves around whether to include Indra and Bali (as well as Sugriva) in the counts. The ambiguity in the numbers of asuras and devas could reflect an understanding that, depending on the year, the calendar dates that the equinoxes and solstices fall on will differ (see for example, Royal Museums Greenwich n.d.). Also, a day or so before and after the solstices, the incremental movement of the Sun north or south appears to "stand still". Hence, counts based on naked-eye observations a day or so before and after the technical solstice date would result in either shorter or longer day counts between events.

Perhaps the most revealing aspect of the bas relief for the present discussion, however, concerns the number of oversized asuras and devas shown tugging on the churning serpent-rope. There are three such figures on either side of the pivot point. According to Mannikka $(1996,39)$, the "[t]hree oversize figures depicted on each side of Mount Mandara divide the churning scene into six segments representing the 6 months between December 22 and June 21". In my opinion, the symbolism of the six oversized asuras and devas, combined with Mannikka's $(1996$, figs. $5.38,5.43)$ photographic documentation of sunlight falling on the two deities on either end of the panel on the solstice dates, plus the suggested day count, together support the proposal that among other things, the "Churning of the Ocean of Milk" relief represents the relationship between the equinoxes and solstices and, ultimately, the bounding parameters of the Angkor cosmos. Indeed, if we take into account the three- or four-day celebration time following the equinox, or perhaps the caveats noted above, then arguably the proffered interpretation works well enough to convey the relevant temporal relationships in the greater context of the creation story.

The day count on the panel might not be what an archaeoastronomer might devise. And there are alternative explanations: Barnhart and Powell (2013, 12-13), for example, suggest that the large deities on either end of the serpent-rope are not Bali and Sugriva, 
but, rather, Ravana and Hanuman from the Hindu Ramayana story. They further propose that Vishnu at the centre does not sit at an equinox, but rather at the summer solstice, with the day count of 57 and 59 from Vishnu to the two large deities on either side representing dates of zenith passage at Angkor.

In Hindu cosmology, the concept of balance between opposite forces (for example, light versus dark, good versus evil, gods versus demons) is fundamental (Michell 1988, 22-23). Accordingly, and with respect to the Angkor Wat relief, I tend to favour an interpretation of Vishnu centred at an equinox, mediating opposite forces represented by the solstice extremes. But in either case, the two interpretations are not mutually exclusive in the sense that both Mannikka (1996) and Barnhart and Powell (2013) find the solstices incorporated in the relief at critical turning points. Indeed, the significance of the solstices in the imagery by either interpretation supports the importance of the solstices to the overall design of Angkor temples - which was the point of the main article.

\section{References}

Barnhart, E. and C. Powell, 2013. "The Importance of Zenith Passage at Angkor, Cambodia” [online]. Accessed July 2019, http://mayaexploration.org/pdf/angkorzenithpassage.pdf

Faraut, F. G., 1910. Astronomie Camdodienne. Saigon: F. H. Schneider.

Mannikka, E., 1996. Angkor Wat: Time, Space, and Kingship. Honolulu: University of Hawai'i Press.

Michell, G., 1988 [1977]. The Hindu Temple: An Introduction to its Meaning and Forms. Chicago: University of Chicago Press.

Romain, W. F., 2018. "Solstice Alignments at Angkor Wat: Connecting to the Cycles of Time". Journal of Skyscape Archaeology 4 (2): 176-200. https://doi.org/10.1558/jsa.35712

Royal Museums Greenwich, n.d. "When is the Summer Solstice?" [online]. Accessed August 2019, https:// www.rmg.co.uk/discover/explore/equinoxes-and-solstices

Time and Date, 2019. "Solstices and Equinoxes" [online]. Accessed August 2019, https://www.timeanddate. com/calendar/seasons.html

Wilson, H. H., trans., 2015 [1864]. The Vishńu Puráńa: A System of Hindu Mythology and Tradition, vol. 1. London: Forgotten Books [facsimile of London: Trübner].

Zhou, D., 2007. A Record of Cambodia: The Land and Its People. Trans. by P. Harris. Chiang Mai, Thailand: Silkworm Books. 